\title{
Ready or not, here we come
}

\author{
Job transitions during a pandemic
}

n March 2020, the library world ground to a halt along with other parts of life in the United States. Library staff were immediately busy figuring out how to work from home and how to provide services during this challenging time. Librarians transitioned to remote work, brought equipment home, and developed new procedures. Colleagues retired, left, and even died. Once the initial panic passed, libraries slowly started hiring.

We both got new jobs during the pandemic and moved to start new positions. We both previously worked at the University of Illinois-Chicago (UIC), an urban research university supporting more than 30,000 students, where Gregory was the head of the technical services department and Khodarahmi supervised access services at the Daley Library. This process was certainly daunting. Buying and selling homes, packing, and moving is a lot of work any time, and the pandemic made it even harder.

Getting oriented to a new community during a lockdown is tough. We faced new challenges, many of which will endure in the future. Libraries' pandemic experiences brought change in hiring and employment practices as well as in other areas. As librarians working and managing staff in different functional areas (public services and technical services/collection management), we see many possible effects.

\section{Gregory's experience}

I interviewed in person at Northern Illinois University (NIU), located in DeKalb, early in March 2020. It was Spring Break and campus was eerily deserted, foreshadowing what was to come. I started work at NIU on September 1t, 2020, and moved to my new home on September 11. By this time, the library had settled into pandemic routines. However, with the start of the academic year in fall 2020, as well as the new fiscal year, issues arose regarding the collections budget. Purchase of materials needed for courses was prioritized, with items for faculty research second. The library budget picture was somewhat uncertain in the fall, as the university administration made decisions about finances for the year. At times during the 2020-21 academic year I have been able to go into the library to work in the office, although meetings have remained remote.

In my position as associate dean for collections management, I supervise technical services, special collections, and digital programs. I met at least once with every staff member in my division, although this is no substitute for getting acquainted in person. I was also able to visit most of the physical areas in person, including Rare Books and Special Collections, the Southeast Asia Collection, and Technical Services. However, in November 2020, the pandemic surge forced most staff to work from home full time until late in the spring. Much work has been so disrupted that it is impossible to get a true understanding of it until more staff return to on-site work. For example, the switch to online courses increased the demand for e-books greatly, and the library ordered as many materials in online format as possible. This changed the technical services workflow, with many fewer

\footnotetext{
Mozhdeh Khodarahmi is associate library director of access, instruction, and research services at Macalester College, email: mkhodara@macalester.edu, Gwen M. Gregory is associate dean for collections management at the Northern Illinois University Libraries, email: ggregory@niu.edu
}

(c) 2021 Mozhdeh Khodarahmi and Gwen M. Gregory 
print materials being received. It is uncertain whether this will change when more in-person classes return. Quarantines as well as shipping and supply delays also affected technical services. Several tasks that cannot be easily done remotely, such as evaluating the preservation workflow, have been set aside for future analysis. Campus budgets became uncertain as the future of student enrollment was up in the air. The library chose to make changes to our FY21 materials budget, due to this uncertainty and to accommodate pandemic demands like streaming video and e-books. I faced the extra challenge of learning how the library budget works while not being able to meet with the experts in person.

\section{Khodarahmi's experience}

For the first nine months of the pandemic, I was one of the managers of public services at the UIC's Daley Library. Finding relevant jobs to do remotely for the front desk crew was challenging. The focus was on professional development. I collected open access resources relevant to the job responsibilities and invited staff members to contribute. This effort was well received, and most of the staff members contributed at least one resource, resulting in a robust list of articles, books, webinars, and online training resources.

Meanwhile, the library was migrating their library management system to Alma/Primo and trying to train all staff. I coordinated training and encouraged staff engagement. These activities proved relevant when I accepted the position of associate library director of access, instruction, and research services (AIRS) at Macalester College in Saint Paul, Minnesota, and began work there in January 2021. The interview process was fully online.

This new environment made me rethink procedures and policies for my new institution. It was like playing a familiar game but on a higher level of difficulty, with working remotely for a month and then moving to a new state as an added twist.

Understanding the culture, procedures, regulations, and history of the new institution is critical to thinking strategically on how to move forward. However, there are transferable skills and knowledge that can pave the way. As a member of the leadership team overseeing public services, I started by having one-on-one meetings with my supervisor, peer, and direct reports to get to know everyone, understand their interests and needs, and the environment. Thankfully, everyone was supportive throughout the process. These meetings resulted in a recommended list of external and internal library partners that she needed to communicate with. Next, with my supervisor's help and support, I started networking with those library partners and collaborators to get to know them and learn how their work is interrelated.

Meanwhile, I was evaluating the AIRS operations during the pandemic as well as how to move forward post pandemic. I found these online meetings extremely helpful in understanding how things work in the institution and building relationships with external/internal library partners. Not having in-person interactions made the meetings more formal. The organic conversations before and after meetings, having friendly chats with other colleagues when you bump into each other while passing, and meeting students and feeling the services offered at the library was dearly missed.

To determine a fair and equitable mechanism that allows staff to continue working remotely and ensure work environments are inclusive, schedules were coordinated to enable meetings of various modes and combinations of staff participation (whether they be remote, in-person, or hybrid) throughout the pandemic. Library managers also ensured that expectations of campus stakeholders were adjusted with respect to the in-person/ in-office availability of staff. The results of the leadership discussions were shared in weekly staff meetings, and everyone was invited to share their thoughts. One of the library's strengths is the high level of staff engagement in decision making, and leadership transparency makes the Macalester Library a strong community.

Rethinking physical spaces on campus was another critical issue for me. The library is being renovated to welcome the Digital Resources Center to its lower level. I was included in the planning team and was invited to related meetings. I learned about the physical space using the maps, descriptions, and the Physical Space Renovation Group conversations, without ever being in the library. I moved to St. Paul in February 2021 and 
could better understand what they were talking about. Prior to my hiring, conference rooms were configured with technology enabling seamless collaboration between in-person and remote employees. Employees without permanent desk setups needed places to work when on campus. A set of processes and procedures was established to ensure all staff have the equipment and technology needed to perform their jobs within these new scenarios.

Library instruction sessions, as well as information literacy workshops for faculty and students, were offered asynchronously and synchronously during online classes. Finding the best methods for asynchronous sessions required exploring online learning and reimagining the structure of the training. Some librarians needed new skillsets. Reference and instruction librarians embraced this opportunity and found creative solutions to offer the services to the community while learning the new tools. Consultations for faculty and students have been offered via online platforms such as Zoom and Google.

\section{Impacts of the pandemic}

Professional development has changed in a few ways. It is recognized as fully essential, due partly to the fact that when working remotely library employees participated in many more professional development activities. Library conferences were forced to adopt fully online formats, which allowed many more to participate at lower costs than attending in person. In the future this will lead to hybrid format conferences and professional development options, where participants may attend in person or virtually, making them available to a much wider audience.

One of the largest areas of change is remote work. Few librarians worked remotely prior to the pandemic. Now that many have experienced remote work, it will be hard for some to go back to working on-site all the time. There will probably be many variations on the hybrid schedule, with plenty of librarians working from home part of the time. New policies and procedures need to be developed to cover telecommuting. Libraries will probably have to follow the lead of their larger institution on this, as many colleges and universities are now developing campus telecommuting policies. Equity issues may arise in this area as some library jobs are not possible to do remotely, while some are. These issues require careful consideration, not simply assuming some workers cannot do remote work. We will need to look closely and develop clear policies and procedures. New hires may have increased expectations about working remotely, which should be discussed as part of the interview and hiring process. Remote work will necessitate work technology at home-e.g., the work laptop is rapidly replacing the less mobile desktop workstation.

Pandemic experiences have certainly given new insights about the hiring and onboarding process. There will likely be permanent changes to the way everyone views hiring in the future, and many are applicable to academic libraries. First, the interviewing process can be different. We can make much greater use of online video tools (e.g., Zoom). However, remember that not everyone has the same technology or quiet surroundings available. We have learned this about students, and we must also keep it in mind about applicants. To promote equity, we should accommodate the needs of interviewees by offering technology help and being flexible about scheduling. The onboarding process has evolved to incorporate electronic submission of documents and online orientation.

Hopefully, these improvements will remain, making the process more convenient for new employees and alleviating the need to visit different offices in person when starting work. Increased automation of processes, from timesheets to invoices, will hopefully result from changes forced on us during the pandemic. We would all love to be freed from tedious paper-based processes that seem based on decades-old rules. As workers are hired as full or partial telecommuters, the onboarding process should evolve to make them into successful parts of the organization, just as those who work on-site are.

We are both doing well in our new positions. After being on the pandemic edge of academic library work, some things we took for granted seem precious, and some we do not miss at all. Our experiences starting new jobs during the pandemic have given us insight into the future of academic libraries and how our work is evolving. $\mathrm{z}$ 